elderly Congolese patient with severe osteoarthritis has found a French-speaking family physician near her home. She makes a short, thankful speech, and this time I don't dismiss the gratitude as grossly disproportionate to what I've done for her. "Every visit, I felt better just to see you," she says. She hugs me; I feel very slight. She presses her cheek against mine and I can feel and smell her hair. "Don't forget me," she says through the interpreter. "Come visit my home."
Weeks later, I see my doctor again. I'm doing much better, and he seems mystified as to why I've come. I wanted to check in, I explain. I can see him trying to figure out what I really want from him, thinking we're doing the doctor-doctor visit dance, where he must guess the investigation, referral or prescription I have in mind. He offers a medication, and I decline. He offers a different one, but I don't want any medications. He asks again why
I've come. He has no idea, I realize, no idea how therapeutic his presence is. I don't want to alarm him, so I don't give him the simplest answer: that all I needed, quite literally, was to see the doctor.

\section{Martina Scholtens MD \\ Bridge Refugee Clinic \\ Vancouver Coastal Health \\ Vancouver, BC}

CMAJ 2011. DOI:10.1503/cmaj.100535

\title{
Skills and mysteries
}

\section{Complete Physical \\ Shane Neilson \\ The Porcupine's Quill; 2010.}

$\mathrm{D}$ octors have a hands-on relationship with the big mysteries - or seem to. Perhaps family doctors do especially. The subjects of their professional lives are the traditional subjects of poetry. So when doctors write poems, it seems in keeping.

Shane Neilson is a family physician and he gets some poetic things right here. He knows that skill so often falls apart to offer only, helplessly, love. His book is an argument for love's rightful place among the skills and mysteries.

Love again. Damn. It's more important than your sore throat, than your cough.

Also, to his credit, the doctor writes about doctoring. He sticks to what he knows. He sticks to what he admits to not knowing.

Humility salvages some of these poems from being imitative fossils. Outright prose ("Self-diagnosis makes my job easier.") will be found cohabiting near strained poeticisms ("in the dementia of meaningfully"). Yet honesty and beauty, in natural rhythms, break through cleverness in lines here and there:

I saw a man clutching his chest, saw coughing children playing with ancient toys ...I sleep, dreaming of iron men drowning in Kailua-Kona Bay.

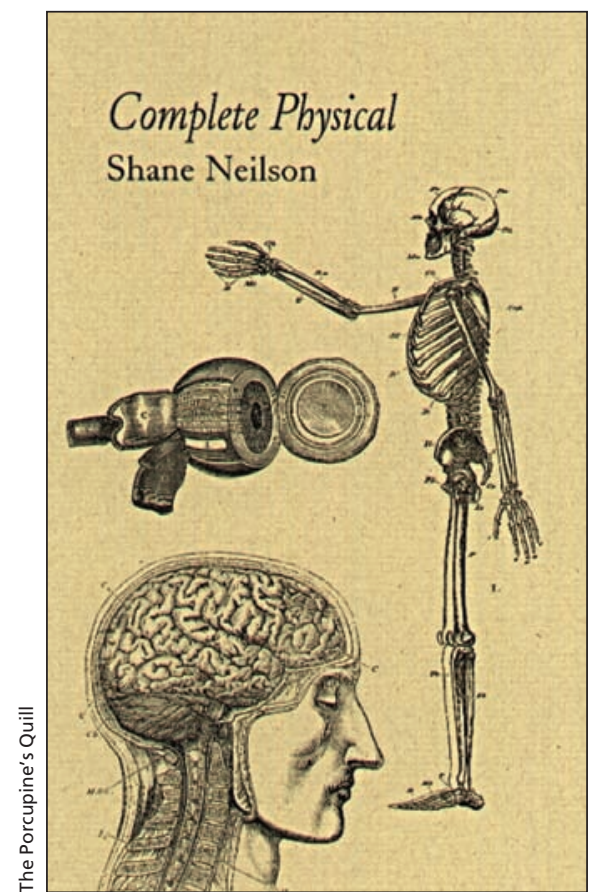

Neilson also gets points for "revisiting" a few of his poems, such as "My Illness, Revisited." In these, presenting variations on a theme, he admits a seeking impulse. For an instant, he keeps closure ajar. The two best poems here are "Inside the Examining Room" and "All Pain Can Be Controlled." They do not gush or cramp.

But shouldn't an editor have suggested dropping "Christ Child in an Incubator" for its showboating, "Dr. Grinch" and "Fairygodmother, MD" for their silliness, or the rhyming verse that opens and closes this book?

The Porcupine's Quill designs and prints elegant books and this one sports old anatomical illustrations throughout - but in its poetry stable, this press tends to be fuddy-ish, staid. In wordchoice and rhythms, there are nods to Dr. Shakespeare and Dr. Dickens. There is a tendency to repeat short phrases, in an emphatic pacing, as if a speech were being eked out for applause. The fallacy of humanity in all things rears its ageold specter when a breathing tube, or some drawings in an old medical textbook, are addressed as "you." A reader will also find archaisms such as "forsooth," "verily," and the un-ironic "O."

But there is wisdom here, too. "Think of pain, not flocks." "Intellect is not a church." A good doctor is ruminating.

There is professional company to be had. Any doctor-reader who perseveres, will be rewarded by sincere and touching lines such as these:

At twenty-five, degree on my wall,

I looked to yellowed yards of textbooks for wisdom, and found data only.

There is no preparation: people die, and I solder silver linings to grief.

\section{Phil Hall}

Poet

Perth, Ont.

Phil Hall's latest book is The Little

Seamstress (Pedlar Press; 2010).

CMAJ 2011. DOI:10.1503/cmaj.101384 